http://jmscr.igmpublication.org/home/

ISSN (e)-2347-176x ISSN (p) 2455-0450

crossref DOI: https://dx.doi.org/10.18535/jmscr/v7i7.44

\title{
Evaluation of efficacy of Triamcinolone Acetate Intra Articular Therapy for Knee Osteoarthritis: A Case Control Study
}

\author{
Authors \\ Dr MD. Jaan Basha ${ }^{1}$, Dr Venkat Lakavath ${ }^{2}$ \\ ${ }^{1}$ Assistant Professor, Department of Orthopaedics, Princes Esra Hospital, Deccan College of Medical \\ Sciences, Hyderabad, Telangana State \\ ${ }^{2}$ Associate Professor, Department of Orthopaedics, Government, Medical College, Nizamabad, \\ Telangana State \\ *Corresponding Author \\ Dr Venkat Lakavath
}

\begin{abstract}
Knee osteoarthritis constitutes a public health concern of immense dimensions, and places a burden on society similar to few other conditions. Corticosteroids are used for treatment. The aim of this study is to evaluate efficacy of intra-articular triamcinolone injections for osteoarthritis of the knee. This is a double blind, prospective, randomized, and controlled study conducted at Deccan college of medical sciences, Hyderabad after obtaining permission from the hospital ethics committee. This study includes 60 patients of both sexes aging from 50-70 years. These patients were divided in two groups randomly by the closedenvelope technique. Diagnosis was done using Kellgren and Lawrence scale for osteoarthritis. The efficacy of pain relief in the 2 groups were compared using Visual analog score (VAS), Oxford knee Score and McGill Quality of life score followed upto 6 months. The study group was given 40mg of $1 \mathrm{ml}$ triamcinolone acetate and compared with control normal saline. The base line parameter VAS scores $(6.03 \pm 1.36$ $\& 6.43 \pm 1.02)$ Oxford knee Score $(44.46 \pm 4.02 \& 45.23 \pm 5.23)$ and QOL scores $(86.03 \pm 4.36$ and 85.36 \pm 5.32$)$ were comparable. The use of triamcinolone decreased the pain and pain relief was satisfactory to patients and it also improved the Quality of life score up to 6 months.
\end{abstract}

Keywords: Osteo-arthritis; intra-articular injection; steroid; triamcinolone acetonide.

\section{Introduction}

Osteoarthritis is the single most common cause of disability in older adults, with $10 \%$ of patients aged 55 or more having painful disabling osteoarthritis of the knee, a quarter of whom are severely disabled. ${ }^{[1]}$ With no cure, treatment is directed at pain relief and improvement or maintenance of function. Emphasis has been placed on the development of diseasemodifying approaches that can revert or at a minimum delay the progression of the disease. ${ }^{[2]}$
Osteoarthritis (OA) is a chronic degenerative disorder of multifactorial etiology characterized by the loss of articular cartilage, hypertrophy of bone at the margins, subchondral sclerosis, and range of biochemical and morphological alterations of the synovial membrane and joint capsule. Typical clinical symptoms are pain, particularly after prolonged activity and weight-bearing; whereas stiffness is experienced after inactivity. 
When the arthritis becomes symptomatic and painful, drug therapy can then become useful. a wide range of very different drugs, especially nonsteroidal anti-inflammatory drugs (NSAIDS) in combination with other medications (e.g.proton pump inhibitors), opioid analgesics, potentially cartilage active agents and phytopharmaceuticals, have all found to be useful. Topical agents are also popular since they exert fewer systemic side effects and enjoy a high level of acceptance amongst patients. In addition, glucocorticoids and hyaluronic acid preparations number amongst those medications used for intra-articular OA therapy.

The need for an intra-articular injection to treat knee $\mathrm{OA}$ requires critical consideration given its invasive nature. Prerequisites for implementing an intraarticular injection include a reliable mastering of the atraumatic injection technique and the observance of all hygiene rules described in the guidelines for intra-articular punction and injection. Despite even the most careful implementation, each intra-articular injection carries the risk of an iatrogenic infection, where this usually involves staphylococci. Glucocorticoids and hyaluronic acid preparations in particular have to be named among the medications used for intra-articular OA therapy.

In addition to 'standards of care', such as weight loss, physical therapy, analgesics, activity modification, and strengthening exercises, intraarticular corticosteroids remain one of the mainstays of treatment utilized in clinical practice. ${ }^{[3]}$ Clinical evidence suggests that benefit is short lived, usually one to four weeks. Most patients ( 80\%) with symptomatic knee osteoarthritis show a therapeutic response to intra-articular injections of corticosteroids, therefore, the debate is centered upon the longevity of symptom relief. ${ }^{[4]}$ Concern has been expressed that long term treatment could promote joint destruction and tissue atrophy. ${ }^{[5]}$ Studies of cartilage damage, however, tend to suggest that changes are more likely due to the underlying disease than the steroid injection. ${ }^{[6]}$ This is a randomised controlled trial in which the efficacy of intra-articular corticosteroid triamcinolone injections for osteoarthritis of the knee is evaluated.

\section{Material and Methods}

This is a double blind, prospective, randomized, and controlled study conducted at Deccan College of medical sciences, Hyderabad after obtaining permission from the hospital ethics committee. This study includes 60 patients of both sexes aging from 50-70 years. These patients were divided in two groups randomly by the closed-envelope technique. Diagnosis was done using Kellgren and Lawrence scale ${ }^{[7,8]}$ for osteoarthritis. Analysis was done based on the X-ray grading. Grade 1 was considered sub-threshold for OA. Grade 2 and 3 were considered as a positive finding for $\mathrm{OA}$.

Patients of age $<40$ years, RA, inflammatory arthritis, Gout, bilateral end stage, unable to walk without aids, systemic lupus erythematosus, polyarthralgia, previous history of fracture of lower limb or spine, any other surgical or medical condition that severely limits subjects' functional ability were excluded from study.

At the screening visit, patient's medical history was taken and clinical assessment was done in detail. The knee joint was examined on the grounds of local examination and specific parameters for assessing the severity of arthritis subjectively as well as objectively. Before the procedure, baseline VAS score was measured and baseline quality of life (QOL) score was measured by filling McGill QOL questionnaire. ${ }^{[9]}$ An anesthesia technician, other -wise not involved in the study, prepared the injections depending on the group allocated. Group $\mathrm{T}$ patients received solution consisted of $40 \mathrm{mg}(1 \mathrm{ml})$ triamcinolone acetonide, and control group $\mathrm{C}$ received $1 \mathrm{ml}$ of normal saline.

The patients were laid supine with a small pillow or bolster under the knee to place the joint in mild flexion. The part was cleaned properly and draped under proper aseptic conditions. Using anterolateral approach, anterior aspect of the knee was palpated to locate the patellar tendon. Moving $1 \mathrm{~cm}$ lateral to patellar tendon, a depression was present which marked the entry point of needle. A $10 \mathrm{ml}$ syringe 
with 21-gauge needle was used. The needle was placed perpendicular to the skin with tip of needle directed at $45^{\circ}$ angle into the center of knee. The placement of needle was confirmed by C- arm. The needle was aspirated to look for any fluid.The drug was then injected into the joint space depending on the group allocated.

\section{Results}

A total of 200 patients were included in this study. All the This is a double blind, prospective, randomized, and controlled study conducted at Deccan College of medical sciences, Hyderabad after obtaining permission from the hospital ethics committee. This study includes 60 patients of both sexes aging from 50-70 years. The demographic parameters and osteoarthritis grade and use of analgesics were shown in table 1 . The age and sex distribution in both groups were comparable. Table 3,4,5 shows Oxford knee scores, visual analog scores and McGill QOL scores. There was no significant difference in the baseline Oxford knee scores, VAS scores and QOL scores in both groups.

Table 1: Demographic features

\begin{tabular}{|l|c|c|}
\hline Base line characters & Group T & Group C \\
\hline Age in years & $65.5 \pm 7.8$ & $64.7 \pm 8.6$ \\
\hline Gender (male/female) & $9 / 21$ & $11 / 19$ \\
\hline Weight in kg & $72.5 \pm 10.4$ & $73.8 \pm 97$ \\
\hline Height in cm & $163.68 \pm 9.43$ & $158.65 \pm 10.36$ \\
\hline Kellgren/Lawrence scale & & \\
\hline Grade3 & 16 & 20 \\
\hline Grade 4 of & 14 & 10 \\
\hline $\begin{array}{l}\text { Mean duration } \\
\text { osteoarthritis in years }\end{array}$ & $5.2 \pm 1.6$ & $5.8 \pm 2.1$ \\
\hline Concomitant analgesic use & & \\
\hline Paracetamol & 16 & 18 \\
\hline NSAID & 14 & 12 \\
\hline
\end{tabular}

Table 2: Comparison VAS score in two groups

\begin{tabular}{|l|c|c|}
\hline TIME & Group T & Group C \\
\hline Base line & $6.03 \pm 1.36$ & $6.43 \pm 1.02$ \\
\hline 1week & $1.09 \pm 0.36$ & $6.32 \pm 1.04$ \\
\hline 1month & $2.42 \pm 0.62$ & $6.53 \pm 1.02$ \\
\hline 2 month & $3.06 \pm 0.69$ & $6.23 \pm 1.54$ \\
\hline 3 month & $3.38 \pm 0.25$ & $7.02 \pm 1.65$ \\
\hline 4 month & $3.75 \pm 0.32$ & $7.32 \pm 1.92$ \\
\hline 5 month & $4.02 \pm 0.63$ & $7.56 \pm 1.96$ \\
\hline 6 month & $4.32 \pm 0.78$ & $7.62 \pm 1.65$ \\
\hline
\end{tabular}

There was significant decrease in pain, VAS score were improved when compared to control groups.
Table 3: Oxford knee score

\begin{tabular}{|l|c|c|}
\hline TIME & Group T & Group C \\
\hline Base line & $44.46 \pm 4.02$ & $45.23 \pm 5.23$ \\
\hline 1 week & $40.12 \pm 4.56$ & $44.52 \pm 5.78$ \\
\hline 1 month & $39.23 \pm 3.02$ & $45.89 \pm 4.23$ \\
\hline 2 month & $35.58 \pm 5.02$ & $41.36 \pm 4.25$ \\
\hline 3 month & $30.27 \pm 5.69$ & $40.23 \pm 6.36$ \\
\hline 4 month & $30.59 \pm 6.14$ & $42.36 \pm 3.25$ \\
\hline 5 month & $29.20 \pm 7.02$ & $44.96 \pm 5.36$ \\
\hline 6 month & $27.37 \pm 8.25$ & $42.32 \pm 7.23$ \\
\hline
\end{tabular}

There was decrease in mean oxford knee score from baseline in both the groups, and it was lower in group $\mathrm{T}$ as compared to $\mathrm{C}$ group at all intervals. The difference in the score between both the groups was also statistically significant $(\mathrm{P}<0.05)$ at all the follow-up time intervals.

Table 4: Comparison QOL score in two groups

\begin{tabular}{|l|c|c|}
\hline TIME & Group T & Group C \\
\hline Base line & $86.03 \pm 4.36$ & $85.36 \pm 5.32$ \\
\hline 1week & $80.09 \pm 4.36$ & $84.32 \pm 6.21$ \\
\hline 1 month & $79.42 \pm 3.62$ & $82.12 \pm 3.12$ \\
\hline 2 month & $73.0 \pm 4.69$ & $83.21 \pm 5.23$ \\
\hline 3 month & $71.38 \pm 5.25$ & $80.98 \pm 4.23$ \\
\hline 4 month & $69.75 \pm 3.32$ & $81.23 \pm 4.23$ \\
\hline 5 month & $64.02 \pm 5.63$ & $82.96 \pm 4.59$ \\
\hline 6 month & $61.32 \pm 3.78$ & $85.32 \pm 2.41$ \\
\hline
\end{tabular}

At all the time intervals, mean QOL scores were lower in $\mathrm{T}$ group as compared to $\mathrm{C}$ group. The difference between both the groups was also statistically significant $(\mathrm{P}<0.05)$ at all the followup time intervals.

\section{Discussion}

Only one injection usually being given in clinical trials and at a lower dose $(20 \mathrm{mg})$ than the $40 \mathrm{mg}$ triamcinolone recommended by the American College of Rheumatologists. ${ }^{[3]}$ A dose of $20 \mathrm{mg}$ triamcinolone (equivalent to $25 \mathrm{mg}$ of prednisone) seems to be efficacious for pain control at two weeks. In one study used $40 \mathrm{mg}$ triamcinolone, and this found a benefit at 24 months for night pain and stiffness on one scale but not on another ${ }^{[5]}$.

Dieppe et $\mathrm{al}^{[10]}$ studied Bilateral symptomatic osteoarthritis of knees in adults with mean 65 years,includes eight females and four males. Most had grade 2-4 radiographic changes. Duration of osteoarthritis was 7.5 years. Intra-articular steroid injection (triamcinolone hexacetonide $20 \mathrm{mg}$ ) compared with placebo (saline) and noticed that small, transient reduction in pain and tenderness 
compared with placebo. At one week, subjective improvement in 10/12 in experimental group, 1/12 in control group. Visual analogue scale at one week: mean 36 (SD 29) in experimental group, 70 (30) in control group.

Friedman 1980, ${ }^{[11]}$ United States studied osteoarthritis in 42-75 years patients showing mild to moderate changes on radiograph 42-75 years; mean duration of osteoarthritis 24 months for corticosteroid group and 36 months for placebo group. Intra-articular steroid injection (triamcinolone hexacetonide $20 \mathrm{mg}$ ) compared with placebo (saline); Steroid provided short term pain relief; at one week but not at 4, 6, 8 weeks.

Raynauld 2003, ${ }^{[5]}$ studied Kellgren and Lawrence grade 2 or 3 osteoathritis patients, Mean duration of osteoarthritis 9.8 years for corticosteroid group and 8.7 years for placebo group. Intra-articular steroid injection (triamcinolone $40 \mathrm{mg}$ ) and placebo (saline) every three months for two years; Patients showed benefit for night pain and stiffness. At one year patient visual analogue scale: 34.32 in experimental group, 31.1 in control group.

In our study also there was improvement in pain relief and decreased VAS score significantly compared to control group up to 6 months, comparable to above studies.

The Oxford knee score also recorded by questionnaire $^{[12]}$. In a study compared Oxford knee score in triamcinolone and Botulinum toxin type A (BoNT-A) is a new therapeutic option for treatment for refractory OA knee joint pain. it was seen that there was no significant difference in pain relief as measured by the Oxford Knee score up to 2 weeks. From 4 weeks to 6 months, triamcinolone patients fared much better in terms of pain relief than Group B with a highly significant value of $P \leq 0.001$ from 6 weeks to 6 months. ${ }^{[13]}$

In some studies ${ }^{[5,14,15]}$ found an improvement in WOMAC function score which is in agreement with the findings of a decrease in QOL scores in our study . In a study singh et $\mathrm{al}^{[16]}$ compared triamcinolone alone and triamcinolone with lignocaine also there is decrease in QOL scores Buyuk et al. ${ }^{[17]}$, Jain and Jain ${ }^{[16]}$ also reported that
IA steroid,

i.e.

triamcinolone

and

methylprednisolone are effective at improving function in patients with OA knee. also found an improvement in the WOMAC scores with steroids which were comparable in both triamcinolone and methylprednisolone groups.

Repeat administration of triamcinolon extended Release (TA-ER) using a flexible dosing schedule timed to patient response was well tolerated, with no radiographic evidence of cartilage impact, suggesting that TA-ER injected intraarticularly into the affected knee may be an effective non-opioid treatment option. ${ }^{[14,15]}$

\section{References}

1. Peat G, McCarney R, Croft P. Knee pain and osteoarthritis in older adults: a review of community burden and current use of primary health care. Ann Rheum Dis 2001;60:91-7.

2. Kiadaliri AA, Lohmander LS, Moradi-Lakeh $\mathrm{M}$, et al. High and rising burden of hip and knee osteoarthritis in the Nordic region, 1990-2015. Acta Orthop 2018; 89: 177-183.

3. Lespasio M, Piuzzi NS, Husni ME, et al. Knee osteoarthritis: a primer. Perm J 2017; 21: 16-183.

4. JAMA. Two new intra-articular injections for knee osteoarthritis. Med Lett Drugs Ther 2018; 60: 142-144.

5. Raynauld J,Buckland-Wright C,Ward R,Choquette D,Haraoui B,Martel-Pelletier J,et al. Safety and efficacy of long-term intra articular steroid injections in osteoarthritis of the knee.Arth Rheum 2003;48:370-7.

6. Ayral $X$. Injections in the treatment of osteoarthritis. Best Pract Res Clin Rehumatol 2001;15:609-26.

7. Kellgren JH, Lawrence JS. Radiological assessment of osteo-arthrosis. Ann Rheum Dis. 1957;6:494-501.

8. Altman R, Brandt $\mathrm{T}$, Hochberg $\mathrm{M}$, Moskovitz R. Design and conduct of clinical trials of patients with osteoarthritis. Recommendations from a task force of the 
osteoarthritis research society. Osteoarthritis Cartilage. 1996;4:21-43.

9. Cohen SR, Mount BM, Strobel MG, Bui F.The McGill quality of life questionnaire: A measure of quality of life appropriate for people with advanced disease. A preliminary study of validity and acceptability. Palliat Med 1995;9:207-1

10. Dieppe PA,Sathapatayavongs B,Jones HE,Bacon PA,Ring EF.Intra-articular steroids in osteoarthritis.Rheumatol Rehabil 1980;19:212-7.

11. Friedman DM, Moore ME. The efficacy of intraarticular steroids in osteoarthritis: a double-blind study.J Rheumatol 1980;7:8506

12. Dawson J, Fitzpatrick R,Murray D,Carr A.Questionnaire on the perceptions of patients about knee replacement. J Bone Joint Surg Br 1988,80(1):63-69.

13. Divya Shukla, Smitha K. Sreedhar, and Virendra Rastogi .A Comparative Study of Botulinum Toxin: A with Triamcinolone Compared to Triamcinolone alone in the treatment of Osteoarthritis of Knee. Anesth Essays Res. 2018 Jan-Mar; 12(1): 47-49.

14. Michael J. Langworthy, Philip G. Conaghan, Joseph J. Ruane, Alan J. Kivitz, Joelle Lufkin, Amy Cinar and Scott D. Kelle. Efficacy of Triamcinolone Acetonide Extended-Release in Participants with Unilateral Knee Osteoarthritis: A Post Hoc Analysis. Adv Ther (2019) 36:1398-1411

15. Andrew I. Spitzer, John C. Richmond, Virginia B. Kraus, Andreas Gomoll, Deryk G. Jones, Kim M. Huffman, Charles Peterfy, Amy Cinar, Joelle Lufkin . Scott D. Kelley. Safety and Efficacy of Repeat Administration of Triamcinolone Acetonide Extended-release in Osteoarthritis of the Knee: A Phase 3b, Open-label Study. Rheumatol Ther (2019) 6:109-124

16. Singh S, Kumar S, Hemlata, Chaudhary A, Malik A. A Comparative study of intraarticular injection of steroid versus prolotherapy for pain relief in patients of osteoarthritis knee. Indian J Pain 2019;33:25-30.

17. Buyuk AF, Kilinc E, Camurcu IY, Camur S, Ucpunar H, Kara A. Compared efficacy of intra- articular injection of methyl prednisolone and triamcinolone. Acta Ortop Bras 2017;25:206-8.

18. Jain P, Jain SK. Comparison of efficacy of methylprednisolone and triamcinolone in osteoarthritis of the knee: A prospective, randomized, double-blind study. Int J Sci Stud 2015;3:58-62. 